\title{
Facile synthesis of water-soluble carbon nano-onions under alkaline conditions
}

\author{
Gaber Hashem Gaber Ahmed ${ }^{1,2}$, Rosana Badía Laíño², Josefa Angela García Calzón² \\ and Marta Elena Díaz García*2
}

\author{
Full Research Paper \\ Address: \\ ${ }^{1}$ Department of Physical and Analytical Chemistry, Faculty of \\ Chemistry, University of Oviedo, c/Julián Clavería, 8. Oviedo, 33006, \\ Spain and ${ }^{2}$ Chemistry Department, Faculty of Science, Damanhour \\ University, Damanhour, Egypt \\ Email: \\ Marta Elena Díaz García* - medg@uniovi.es \\ * Corresponding author \\ Keywords: \\ carbon dots; carbon onions; metal-ion sensing; photoluminescence; \\ thermal carbonization
}

Beilstein J. Nanotechnol. 2016, 7, 758-766. doi:10.3762/bjnano.7.67

Received: 23 February 2016

Accepted: 10 May 2016

Published: 27 May 2016

Associate Editor: J. J. Schneider

(c) 2016 Ahmed et al; licensee Beilstein-Institut. License and terms: see end of document.

\begin{abstract}
Carbonization of tomatoes at $240{ }^{\circ} \mathrm{C}$ using $30 \%(w / v) ~ N a O H$ as catalyst produced carbon onions (C-onions), while solely carbon dots (C-dots) were obtained at the same temperature in the absence of the catalyst. Other natural materials, such as carrots and tree leaves (acer saccharum), under the same temperature and alkaline conditions did not produce carbon onions. XRD, FTIR, HRTEM, UV-vis spectroscopy, and photoluminescence analyses were performed to characterize the as-synthesized carbon nanomaterials. Preliminary tests demonstrate a capability of the versatile materials for chemical sensing of metal ions. The high content of lycopene in tomatoes may explain the formation of C-onions in alkaline media and a possible formation mechanism for such structures was outlined.
\end{abstract}

\section{Introduction}

In the last twenty years, carbon based nanomaterials have received much research attention not only from a basic perspective but also from a practical point of view due to their use in a range of applications such as energy storage, tribology, electronics, medicine, catalysis and sensors. The more popular and extensively investigated carbon-based nanomaterials include carbon dots (C-dots), fullerenes, nanotubes and graphene, while others, such as nanodiamonds and carbon onions, stayed forgotten for a long time, in spite of the fact that these carbon nanoparticles (C-NPs) were discovered before the former [1].

C-dots are a special class of carbon nanoparticles that have interesting practical advantages such as low toxicity, relatively small size $(\leq 10 \mathrm{~nm})$, chemical stability, high solubility in water and easy synthesis. Besides, owing to their remarkable photoluminescence (PL) properties, such as broad excitation spectra, 
tunable emission wavelength and stable PL, high stability against photobleaching, $\mathrm{C}$-dots are attracting considerable attention in analytical sensing, bioimaging, photo-reduction of metals and biomedical applications [2-6].

C-dots may be straightforwardly synthetized via two approaches: a) from fine carbon structures (such as multi-wall nanotubes and graphene) by top-down methods and b) by bottom-up approaches from chemical precursors (such as glucose, citrate, ethylenediaminetetraacetic acid) or from natural products (usually vegetables). Recently, using the bottom-up approach, we prepared C-dots based on the thermal carbonization of a mixture of nitrogen-containing organic compounds, ethyleneglycol bis(2-aminoethyl ether)- $N, N, N^{\prime}, N^{\prime}$ tetraacetic acid (EGTA) and Tris, thus providing them not only with surface hydroxy but also with amino groups. These C-dots were successfully employed for sensitive detecting 4-nitrophenol in water [7]. In another work, with the aim to provide surface boronic groups, we prepared C-dots by hydrothermal treatment of a mixture of 6-bromohexylboronic acid, polyethyleneglycol bis(3-aminopropyl)-terminated (PEGA) and 1,2aminopropane (DPA) at $180^{\circ} \mathrm{C}$. We could observe that during the thermal reaction, the boronic groups were unstable and tended to leave the surface of the C-dots. Using these C-dots, reliable determination of tannic acid in wines was achieved with a detection limit of $0.018 \mathrm{mg} \cdot \mathrm{L}^{-1}$ [8].

Carbon nano-onions (C-onions) are another kind of carbon nanoparticles that exhibit outstanding chemical and physical properties. C-onions are spherical carbon shells enclosed within one another (multi-layered fullerenes) with diameters ranging from 3 to $50 \mathrm{~nm}$ [9], depending on the method of synthesis. $\mathrm{C}$-onions have found applications as materials for tribology due to their low friction [10]. Polymers doped with C-onions exhibit increased thermal resistance and can be used as microwave absorbing filters due to the C-onions ability to absorb electro- magnetic radiation in the $26-37 \mathrm{GHz}$ range [11]. Also, $\mathrm{C}$-onions have attracted attention for batteries and supercapacitors, as active materials and/or dispersible conductive additives $[12,13]$. Usually C-onions are obtained by using sophisticated technologies, such as vacuum annealing of nano-diamond precursors [14,15], nano-diamond annealing in inert gases [16], arc discharge in presence of metal nanoparticles [17], high-energy laser excitation of ethylene at high temperatures [18] and chemical vapor deposition using catalysts [19]. There are some excellent reviews devoted to C-onions and their chemistry and applications $[20,21]$. Due to the intricate processes, the running costs and high investment for their synthesis, the use of C-onions for analytical applications is still unexplored. Here, we describe the synthesis and characterization of C-nanoparticles obtained by thermal carbonization at $240{ }^{\circ} \mathrm{C}$ of tomatoes, carrots and tree leaves samples as $\mathrm{C}$-source in absence and in presence of $30 \%$ (w/v) $\mathrm{NaOH}$. We discovered that the use of $\mathrm{NaOH}$ as catalyst favored the formation of $\mathrm{C}$-onions when tomatoes were used as $\mathrm{C}$-source and that intermediate carbon nanostructures were formed when carrots or tree leaves were used. On the basis of the morphologies and spectral characteristics of these structures the formation mechanism of C-onions is proposed. Finally, a preliminary test on the use of such $\mathrm{C}$-onions as sensing materials for metal ions is outlined.

\section{Results and Discussion}

In Figure 1a the HRTEM image reveals that the tomato C-dots synthetized by conventional carbonization are mostly spherical, with diameters well below $1 \mathrm{~nm}$ as also can be observed for $\mathrm{C}$-dots from tree leaves (Figure 1c). In Figure 1b, the HRTEM image shows that $\mathrm{C}$-dots from carrots are also spherical but with diameters around $5 \mathrm{~nm}$.

When using a $\mathrm{NaOH} 30 \%(\mathrm{w} / \mathrm{v})$ media the C-NPs exhibited a different morphology, as can be observed in Figure 2a,b for carrots and tree leaves, respectively. C-dots with no well-
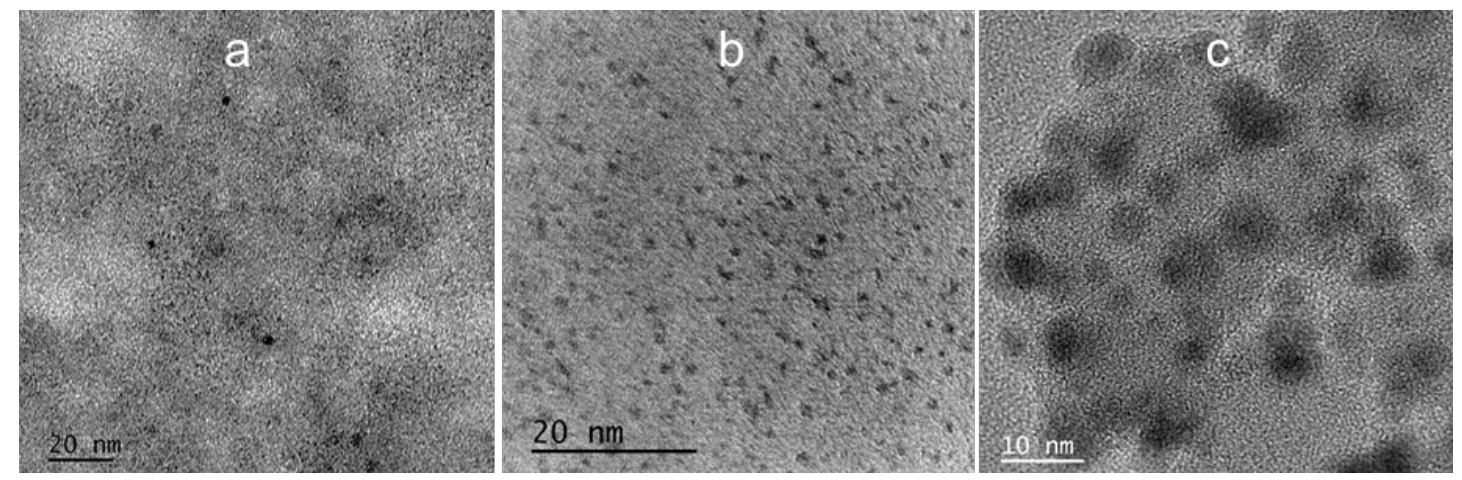

Figure 1: HRTEM images of C-dots obtained by carbonization in aqueous environment, using as carbon source a) tomatoes, b) carrots and c) tree leaves. 

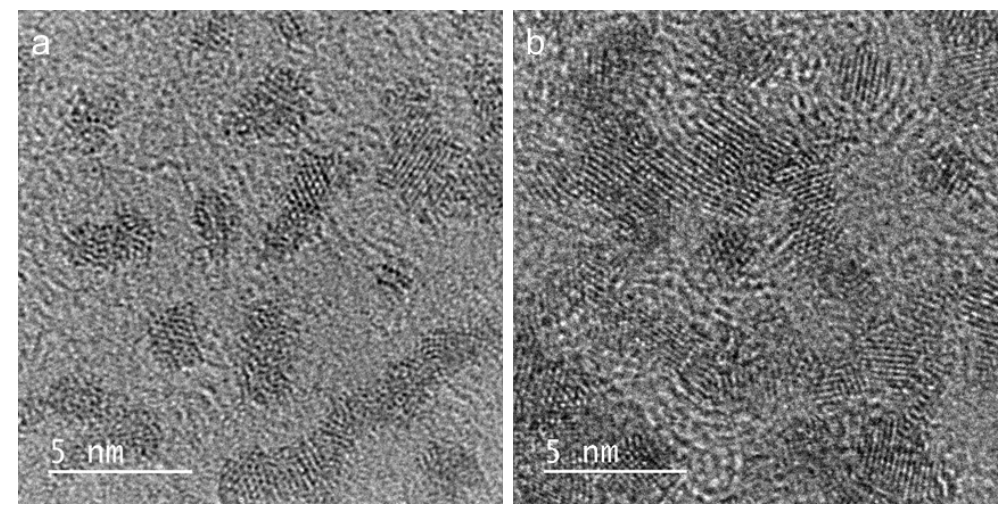

Figure 2: HRTEM images of C-dots obtained by carbonization in $\mathrm{NaOH} 30 \%(w / v)$, using as carbon source a) carrots, b) tree leaves.

defined structure were obtained, in which a crystal order could be observed.

In the case of tomatoes as carbon source, C-NPs clearly show an onion-like structure (Figure $3 \mathrm{a}$ ) for which the interlayer spacings were determined to be about $0.3 \mathrm{~nm}$ by EDX (area highlighted in Figure 3b). This spacing is slightly smaller than the interlayer spacing of (002) planes of graphite [22]. It is worth to mention that along with the $\mathrm{C}$-onions some buckled structures can be observed. Assuming that $\mathrm{C}$-onions grow from the inside to the outside, the buckled sheets can be attributed to carbon layers that do not fit during the growing process of the $\mathrm{C}$-onions. In other words, the layers may not remain spherical during the growth. Continuum mechanical shell models have been applied to investigate the growth limit and buckling patterns of C-onions [23]. To the best of our knowledge, the results shown here, demonstrate for the first time, the possibility of obtaining C-onions from green $\mathrm{C}$-sources just by modifying the carbonization conditions using sodium hydroxide as catalyst.
Figure 4 represents the XRD pattern of the C-NPs produced by the one-step thermal carbonization of tomatoes. For C-dots, a featureless reflection band centered at $2 \theta=21.68^{\circ}$ corresponds to the diffraction of graphite [002] crystal planes and a weak broad peak at about $2 \theta=43^{\circ}$ corresponds to the $\{100 / 101\}$ set of crystal planes [24] of graphite.

The interlayer spacing was determined by using Bragg's equation and was found to be $4.32 \AA$. The mean crystallite size, $L_{\mathrm{c}}$, was determined for the [002] band using Scherrer's equation (Equation 1):

$$
L_{\mathrm{c}}=\frac{K \lambda}{\beta \cos \theta},
$$

where $\lambda$ is the X-ray wavelength (1.5405 $\AA$ ), $\beta$ is the broadening of the diffraction peak measured at half its maximum intensity (in radians), $\theta$ is the scattering angle and $K$ is the Scherrer's constant, which varies with the shape of the crystal-
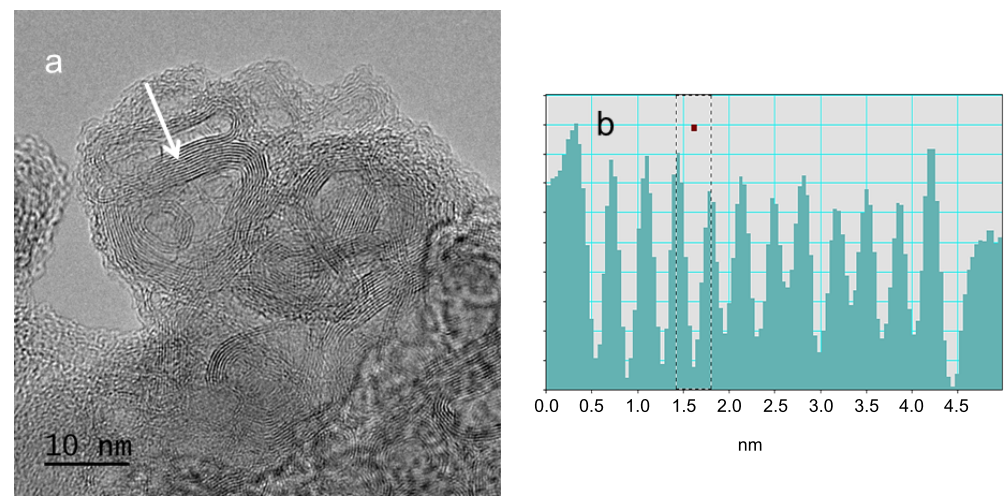

Figure 3: a) HRTEM image of C-onions obtained by carbonization in $\mathrm{NaOH} 30 \%$ (w/v), using tomatoes as carbon source; b) intensity profile (arbitrary units) measured over the white arrow marked in a). 


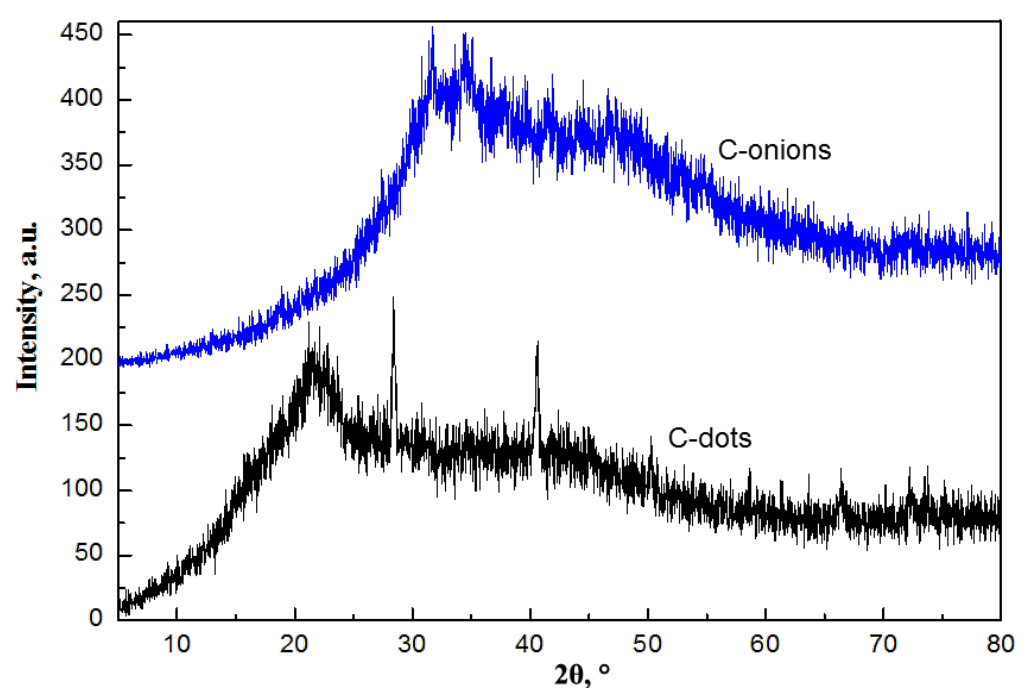

Figure 4: XRD patterns of C-NPs obtained from tomatoes through carbonization in aqueous (C-dots) and $\mathrm{NaOH} 30 \%$ (w/v) (C-onions) media.

lites, from 0.89 for spherical to 0.94 for cubic particles [25]. Considering that this constant is set to 0.9 for particles of unknown size, the $L_{\mathrm{c}}$ was estimated to be $7.4 \AA$ for the C-dots. There is a comparatively large difference to the values reported for graphite (3.34 $\AA$ ), the reason behind which may be poor crystallization and/or formation of misoriented (turbostratic) carbon structures [26]. The XRD spectra of C-dots from carrots and tree leaves showed a similar pattern (Figure S1, Supporting Information File 1).

In the case of $\mathrm{C}$-onions, the diffraction pattern clearly showed that the [2] graphite peak disappeared while new peaks appeared. We ascribed the peak at $33^{\circ}$ to the cubic phase of $\mathrm{K}_{2} \mathrm{O}$ [JCPDS card no. 23-493], taking into account the high concentrations of potassium in these vegetable samples [27]. The peak at $46^{\circ}$ can be ascribed to a rhombohedral phase of graphite corresponding to a [101] reflection, probably due to the introduction of stacking faults in the crystallites with hexagonal stacking upon the $\mathrm{NaOH}$ treatment. The XRD for the C-NPs obtained for tomatoes, carrots and tree leaves by carbonization in $\mathrm{NaOH} 30 \%$ (w/v) media are shown for comparison (Figure S2, Supporting Information File 1). As can be seen, a similar pattern XRD pattern was observed for the three systems, which indicated that similar crystal phases were obtained.

The functional groups of the C-dots were determined by FTIR analysis. In Figure 5, it can be observed that C-onions exhibited very sharp bands at 2926 and $2850 \mathrm{~cm}^{-1}$ due to $\mathrm{C}-\mathrm{H}$

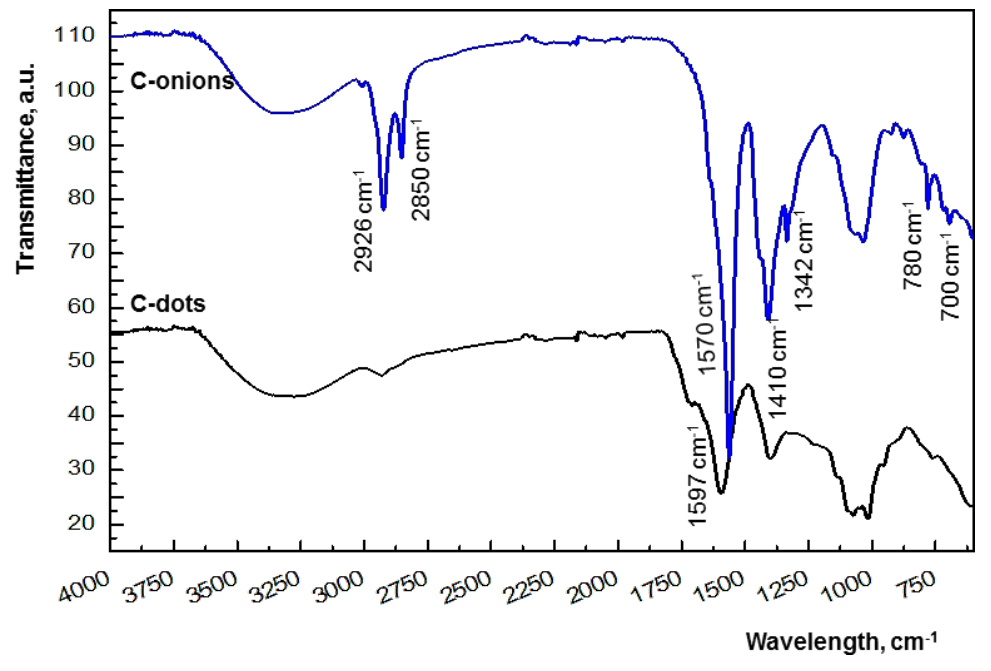

Figure 5: FTIR spectra of C-dots and C-onions obtained by carbonization of tomatoes in aqueous solution and $\mathrm{NaOH} 30 \%$ (w/v), respectively. 
stretch (methylene/methyl) vibrations and aldehyde $\mathrm{C}-\mathrm{H}$ stretching, respectively, while these bands were very weak for C-dots.

The presence of a weak shoulder band at $1720 \mathrm{~cm}^{-1}$ in the $\mathrm{C}$-dots spectrum suggested the presence of saturated aldehyde $\mathrm{C}=\mathrm{O}$ stretching, while this band was not observed in $\mathrm{C}$-onions. On the other hand, the bands at $1170-1600 \mathrm{~cm}^{-1}$ assigned to $\mathrm{C}=\mathrm{C}$ stretching and the peak at $1410 \mathrm{~cm}^{-1}$ attributed to $\mathrm{O}-\mathrm{H}$ bending vibrations (carboxylic acid) can be observed in both types of nanoparticles. The medium-intensity band at $1342 \mathrm{~cm}^{-1}$ observed in C-onions, but not in C-dots, was ascribed to $\delta_{\mathrm{S}} \mathrm{C}-\mathrm{O}-\mathrm{H}$ absorption $[28,29]$. The peak at $1570 \mathrm{~cm}^{-1}$ observed for $\mathrm{C}$-onions can be ascribed to the phenol $\mathrm{C}=\mathrm{C}$ phenol ring stretching. The intense bands observed at 2926 and $2851 \mathrm{~cm}^{-1}$ are characteristics of saturated asymmetric stretching vibrations $\mathrm{CH}_{\mathrm{str}}\left(\mathrm{sp}^{3}\right)$ and symmetric stretching vibrations of $-\mathrm{R}-\mathrm{CH}_{2}=\mathrm{O}$ (aldehyde group), respectively. These two peaks can be hardly observed in the $\mathrm{C}$-dots spectra. The peaks at $1010-1070 \mathrm{~cm}^{-1}$ are from characteristic $\mathrm{C}-\mathrm{O}$ stretchings of primary alcohols. The peaks at 700 and $780 \mathrm{~cm}^{-1} \mathrm{ob}-$ served in C-onions, but not in C-dots, are ascribed to - $\mathrm{OH}$ outof-plane bending vibrations of alcohols. Again, these results demonstrated the possibility of obtaining water-soluble C-onions (due to the presence of carboxy and hydroxy groups) by carbonization in basic media.

The FTIR spectra of the C-NPs obtained when carrots and tree leaves were carbonized in a $\mathrm{NaOH} 30 \%(\mathrm{w} / \mathrm{v})$ media are shown in comparison (Figure S3, Supporting Information File 1). As can be observed, the functional groups of all nanoparticles seemed to be the same, being the only difference the higher intensity of the 2926 and $2850 \mathrm{~cm}^{-1}$ bands for C-onions from tomatoes compared with those of carrots and tree leaves. This may suggest that also $\mathrm{C}$-onions were formed when carrots and tree leaves were carbonized in a $\mathrm{NaOH} 30 \%(\mathrm{w} / \mathrm{v})$ media. Taking into account that with respect to the starting mass of tomatoes, the C-onions average yield was only $(2 \pm 0.5) \%$ and that no C-onions could be observed in the HR-TEM images of tree leaves and carrots, it was reasonable to assume that the $\mathrm{C}$-onions yield from carrots and tree leaves was less than $2 \%$.

The PL spectra of C-dots obtained in aqueous media from tomatoes, at different excitation wavelengths, are shown in Figure S4 of Supporting Information File 1. The maximum emission wavelength depends on the excitation wavelength and is shifted from 438 to $456 \mathrm{~nm}\left(\Delta \lambda_{\mathrm{em}}=18 \mathrm{~nm}\right)$ by changing the excitation wavelength from 300 to $370 \mathrm{~nm}\left(\Delta \lambda_{\mathrm{ex}}=70 \mathrm{~nm}\right)$. It was found that also C-onions obtained in basic media exhibited excitationdependent PL (Figure S4, Supporting Information File 1): The emission maxima shifted from 427 to $440 \mathrm{~nm}\left(\Delta \lambda_{\mathrm{em}}=13 \mathrm{~nm}\right)$ as the excitation wavelength moved from 300 to $350 \mathrm{~nm}$ $\left(\Delta \lambda_{\mathrm{ex}}=50 \mathrm{~nm}\right)$. PL quantum yield of C-dots excited at $362 \mathrm{~nm}$ resulted to be $1.32 \%$ while that of C-onions excited at $328 \mathrm{~nm}$ was $1.63 \%$. These values were similar or even higher than those obtained for carbon dots prepared by the same route of synthesis using different starting materials (Table S1, Supporting Information File 1).

To the best of our knowledge, this is the first report on the synthesis of water-soluble fluorescent C-onions. In order to check the analytical potential of these $\mathrm{C}$-onions as sensing material, their PL response was determined upon exposure to different metal ions and the results were compared with those obtained using C-dots. In Figure 6a, the quenching effect, expressed as $\Delta F=F_{0}-F$, where $F_{0}$ and $F$ are the $\mathrm{PL}$ of the C-onions in absence and presence of a given metal ion, respectively, is shown. As can be seen, $\mathrm{Cu}(\mathrm{II}), \mathrm{Fe}(\mathrm{III})$ and $\mathrm{Hg}$ (II) quenched the $\mathrm{PL}$ of the $\mathrm{C}$-onions, $\mathrm{Fe}(\mathrm{III})$ being the strongest quencher. In the case of C-dots (Figure 6b), Fe(III) was the main quencher and
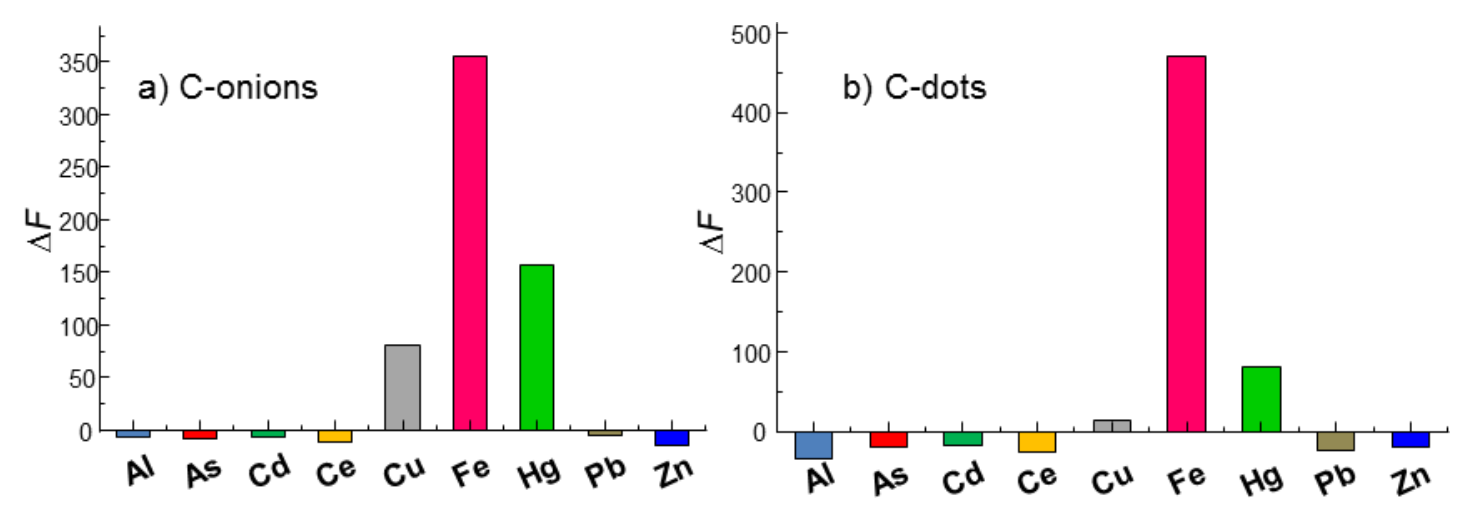

Figure 6: Effect of some metals on the photoluminescence spectra of C-NPs at pH 6. a) C-onions measured at $\lambda_{\mathrm{ex}}=328 \mathrm{~nm}$. Slit width of emission and excitation was 10 and 20 , respectively. b) C-dots measured at $\lambda_{\mathrm{ex}}=362 \mathrm{~nm}$. The slit widths of emission and excitation were both $20 \mathrm{~nm}$. The concentration of metals was $10 \mathrm{ppm}$ in all cases. 
$\mathrm{Hg}(\mathrm{II})$ also quenched to a lesser extent. Consequently, the selectivity against metal ions of the $\mathrm{C}$-onions seemed to be lower than that of C-dots. These results may be explained on the basis of the $\mathrm{C}$-onions structure, with many concentric surfaces exposed for binding, which enhanced the probability for quenching.

Results obtained from the characterization of C-onions suggested that a possible mechanism for the formation of C-onions may be related to the presence of polyene molecules in tomatoes, carrots and leaves, particularly in the case of tomatoes with a high content of lycopene. Under elevated temperatures, oxygen and/or extremes in $\mathrm{pH}$, lycopene molecules may undergo isomerization and oxidation [30,31] and/or break down into small fractions [32]. These products may form fullerenelike embryos which then reorganized into spherical particles composed of concentric graphitic layers (Figure 7), in order to minimize the surface energy of the newly formed edge planes of graphite [9]. Although similar open/closed geodesic structures have been used as models for quantum chemical modelling the growth and the molecular and electronic structures of fullerenes and carbon onions $[33,34]$, the atomic arrangements inducing curvature are still not fully understood. In the case of carrots and tree leaves, the reorganization into onions was not so clear as in the case of tomatoes, although it may be related to the low content of lycopene in these vegetables. We suggest that further investigation of the factors affecting such reorganization must be performed, such as the time of heating, the amount of $\mathrm{NaOH}$ or the temperature used, which also will help to improve the yield of the synthesis.

\section{Conclusion}

$\mathrm{C}$-onions obtained by conventional synthetic methods such as arc-discharge and chemical vapor deposition are insoluble in water, which restricts their use in analytical, biological and biomedical applications. Our results showed that water-soluble C-onions could be prepared by a simple carbonization method using tomatoes as carbon source and $30 \%(w / v) ~ N a O H$ as catalyst. We are aware of the danger of drawing conclusions from preliminary data. However, we sense that this synthetic procedure has the necessary characteristics for further studies and development of tailor-made water-soluble $\mathrm{C}$-onions from polyene molecules with different functionalities in basic media. Given their closed structure, water soluble C-onions could be loaded with specific molecules or drugs in bio-medical applications while the delivery process could be monitored thanks to their exceptional PL properties. The field is open.

\section{Experimental \\ Chemicals and reagents}

All the reagents used were highly pure analytical grade chemicals and used without further purification. $\mathrm{NaOH} 30 \%$ (Prolabo, http://www.vwr.com) was used in the synthesis step. In subsequent steps the following reagents were used: quinine

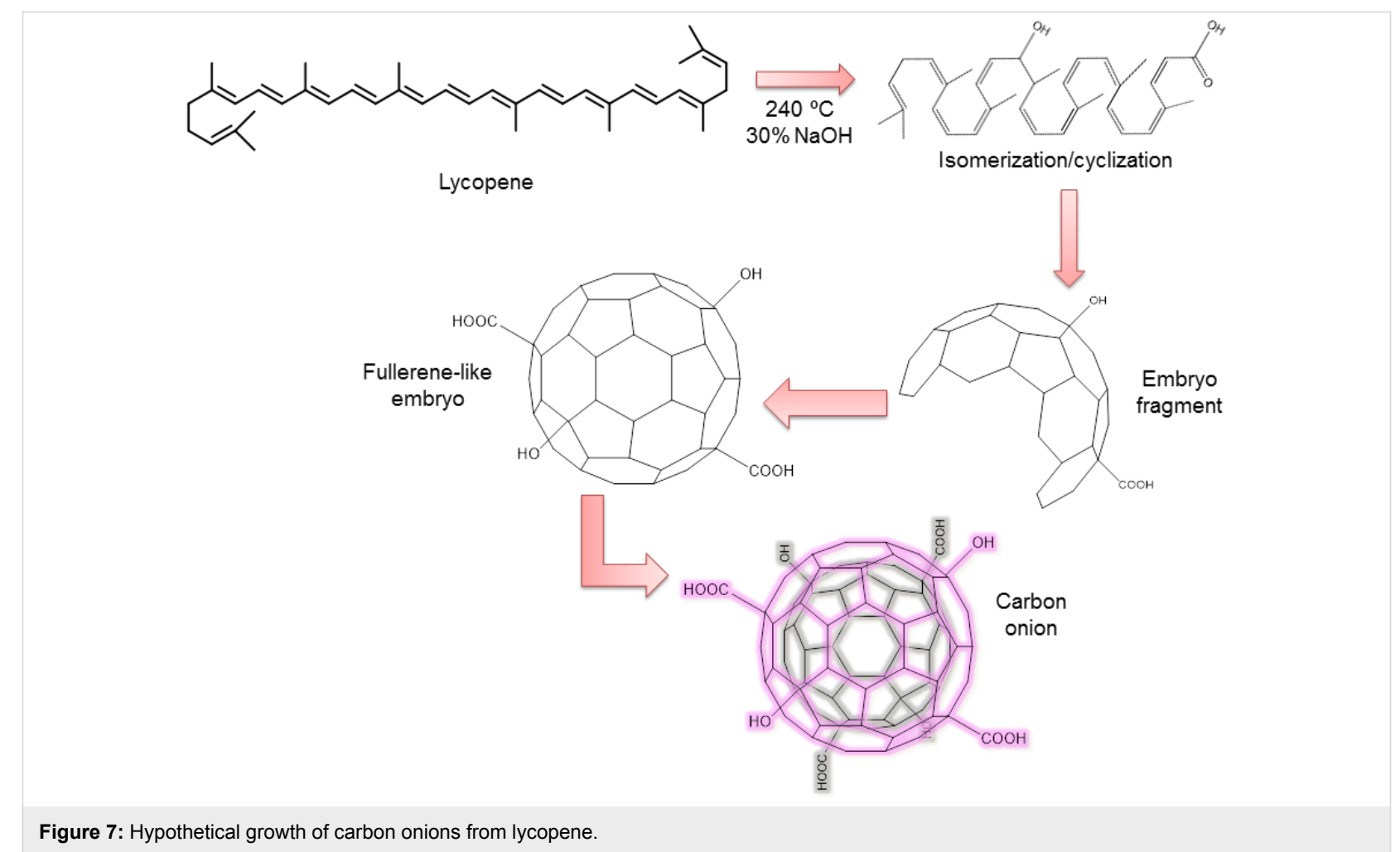


sulfate, $\mathrm{H}_{2} \mathrm{SO}_{4}$, and $\mathrm{Cu}\left(\mathrm{NO}_{3}\right)_{2} \cdot 3 \mathrm{H}_{2} \mathrm{O}$ were purchased from Prolabo, $\mathrm{FeCl}_{3}, \mathrm{ZnCl}_{2}, \mathrm{Na}_{2} \mathrm{HPO}_{4}$ and citric acid were purchased from Sigma-Aldrich, $\mathrm{AlCl}_{3} \cdot 6 \mathrm{H}_{2} \mathrm{O}$ and $\mathrm{Pb}(\mathrm{Ac})_{2} \cdot 3 \mathrm{H}_{2} \mathrm{O}$ were purchased from Montplet \& Esteban S.A., Barcelona (http://www.montplet.es/), $\mathrm{Ce}\left(\mathrm{NO}_{3}\right)_{3} \cdot 6 \mathrm{H}_{2} \mathrm{O}$ was purchased from Fluka, Switzerland, $\mathrm{HgCl}_{2}$ was purchased from Porus (http://poruslabs.com/), and $\mathrm{CdCl}_{2}$ was purchased from The British Drug Houses Ltd., England. Stock solutions containing $100 \mathrm{ppm}$ of the metal were prepared by dissolving the appropriate amount of each salt in distilled/deionized water. Tomatoes (type "Rama") and carrots were purchased from a local market. Tree leaves (acer saccharum) were taken from the faculty garden.

\section{Synthesis of carbon nanoparticles}

C-nanoparticles were synthesized by a thermal carbonization method using tomatoes, carrots and tree leaves as green carbon sources. Typically, after thoroughly cleaning, the starting material was grinded in small pieces and about $30-50 \mathrm{~g}$ was put into dried and cleaned crucibles. In order to prepare C-dots, the homogenized sample was carbonized in a muffle furnace directly at $240{ }^{\circ} \mathrm{C}$ in atmospheric oxygen for $2 \mathrm{~h}$. The residue was then dissolved in about $25 \mathrm{~mL}$ Milli-Q water, filtered through $0.45 \mu \mathrm{m}$ nylon filter and the solution was purified by dialysis through a dialyzer tube (MWCO, 3.5 KDa) for 3 days.

For the synthesis of C-onions $5 \mathrm{~mL} \mathrm{NaOH} 30 \%$ (w/v) was added to the crucible containing the homogenized sample and then transferred into a muffle furnace and heated to $240{ }^{\circ} \mathrm{C}$ in atmospheric oxygen for $2 \mathrm{~h}$. A yellow-brown solid was obtained when carbonizing the samples in the presence of $\mathrm{NaOH}$ $30 \%$. The color is probably due to the partial oxidation of graphene to graphene oxide during the process [35]. The watersoluble part of the residue was extracted by dissolution in $100 \mathrm{~mL}$ deionized water, then filtrated through normal filter papers and followed by nylon filters $(0.45 \mu \mathrm{m})$. The filtered solution was then purified through dialyzer tube (MWCO, $3.5 \mathrm{kDa}$ ) for 3 days. Each purified solution was divided into two aliquots, the first one was dried completely for characterization analysis (dark-brown solid), while the second was used for the analysis experiments.

\section{Photoluminescence measurements}

In a typical procedure, the photoluminescence properties of the C-nanoparticles were evaluated by diluting $200 \mu \mathrm{L}$ of the corresponding C-nanoparticle solution with a $\mathrm{pH} 6$ universal buffer solution ( $0.2 \mathrm{M} \mathrm{Na}_{2} \mathrm{HPO}_{4} / 0.1 \mathrm{M}$ citric acid) to a final volume of $5 \mathrm{~mL}$. The PL spectra were recorded at $456 \mathrm{~nm}$ with excitation at $362 \mathrm{~nm}$ for C-dots. For C-onions the PL measurements were taken at $428 \mathrm{~nm}$ with excitation at $328 \mathrm{~nm}$. For the detection of metal ions, the reaction mixture was prepared by mixing $200 \mu \mathrm{L}$ of the corresponding C-nanoparticle solution and $100 \mu \mathrm{L}$ of metal ion solution (so that the total concentration of metal was $10 \mathrm{ppm}$ ) and then adjusting the volume to $5 \mathrm{~mL}$ with a universal buffer solution pH $6\left(0.2 \mathrm{M} \mathrm{Na}_{2} \mathrm{HPO}_{4} / 0.1 \mathrm{M}\right.$ citric acid $)$. The $\mathrm{PL}$ was measured as mentioned above with the same instrumental settings. A $1 \mathrm{~cm}$ quartz cuvette was used.

\section{PL quantum yield measurement}

The PL quantum yield was calculated through the well-established comparative method using quinine sulfate as a reference. The following equations were used in the quantum yield measurement:

$$
\begin{gathered}
\phi_{\mathrm{C}}=\phi_{\mathrm{st}} \frac{F_{\mathrm{C}}}{F_{\mathrm{st}}} \frac{A_{\mathrm{st}}}{A_{\mathrm{C}}} \frac{n_{\mathrm{C}}^{2}}{n_{\mathrm{st}}^{2}}, \\
\phi_{\mathrm{C}}=\phi_{\mathrm{st}} \frac{G_{\mathrm{C}}}{G_{\mathrm{st}}} \frac{n_{\mathrm{C}}^{2}}{n_{\mathrm{st}}^{2}},
\end{gathered}
$$

where $\phi$ is the quantum yield, $F$ is the calculated integrated luminescence intensity, $n$ is the refractive index, $A$ is the optical density (measured with a UV-vis spectrophotometer, Perkin Elmer, Lambda 900), and $G$ is the gradient of a linear plot of $F$ as a function of $A$. The subscripts " $\mathrm{C}$ " and "st" refer to $\mathrm{C}$-dots (or C-onions) and the reference fluorophore, respectively. Quinine sulphate dissolved in $0.1 \mathrm{M} \mathrm{H}_{2} \mathrm{SO}_{4}(n=1.33)$ with a quantum yield of 0.54 at $\lambda_{\mathrm{ex}}=350 \mathrm{~nm}$ was used as a reference. $\mathrm{C}$-dots and C-onions were dissolved in Milli-Q water $(n=1.33)$.

\section{Instrumentation}

HRTEM (JEOL JEM-2100F, $200 \mathrm{kV}$ ) was used to determine the size and morphology of the synthesized carbon materials. Powder X-ray diffraction studies were performed on a Bruker D8 Discover instrument with $\mathrm{Cu} \mathrm{K} \alpha$ radiation. A Varian 620-IR instrument was used to analyse FTIR spectra on $\mathrm{KBr}$ pellets in the range from 600 to $4000 \mathrm{~cm}^{-1}$. PL spectra were measured using a Cary Eclipse Varian spectrofluorimeter. UV-vis spectrophotometric analysis was measured with Perkin Elmer, Lambda 900 instrument.

\section{Supporting Information}

\section{Supporting Information File 1}

Additional experimental data.

[http://www.beilstein-journals.org/bjnano/content/ supplementary/2190-4286-7-67-S1.pdf] 


\section{Acknowledgements}

Authors gratefully acknowledge financial support from the Ministerio de Economía y Competitividad and Fondo Europeo de Desarrollo Regional (FEDER), Proj\#MAT2012-33690. Also, G. H. Gaber Ahmed thanks an Erasmus Mundus Medastar grant.

\section{References}

1. McDonough, J. K.; Gogotsi, Y. Electrochem. Soc. Interface 2013, 22 (3), 61-66.

2. Baker, S. N.; Baker, G. A. Angew. Chem., Int. Ed. 2010, 49, 6726-6744. doi:10.1002/anie.200906623

3. Esteves da Silva, J. C. G.; Gonçalves, H. M. R. TrAC, Trends Anal. Chem. 2011, 30, 1327-1336. doi:10.1016/j.trac.2011.04.009

4. Li, H.; Kang, Z.; Liu, Y.; Lee, S.-T. J. Mater. Chem. 2012, 22, 24230-24253. doi:10.1039/c2jm34690g

5. Demchenko, A. P.; Dekaliuk, M. O. Methods Appl. Fluoresc. 2013, 1, 042001. doi:10.1088/2050-6120/1/4/042001

6. Hsu, P.-C.; Shih, Z.-Y.; Lee, C.-H.; Chang, H.-T. Green Chem. 2012, 14, 917-920. doi:10.1039/c2gc16451e

7. Gaber Ahmed, G. H.; Badía Laíño, R.; García Calzón, J. A.; Díaz García, M. E. Microchim. Acta 2015, 182, 51-59. doi:10.1007/s00604-014-1302-x

8. Gaber Ahmed, G. H.; Badía Laíño, R.; García Calzón, J. A.; Díaz García, M. E. Talanta 2015, 132, 252-257. doi:10.1016/j.talanta.2014.09.028

9. Ugarte, D. Nature 1992, 359, 707-709. doi:10.1038/359707a0

10. Matsumoto, N.; Mistry, K.; Kim, J.-H.; Erylmaz, O. L.; Erdemir, A.; Konoshita, H.; Ohmae, N. Tribol.-Mater., Surf. Interfaces 2012, 6, 116-120. doi:10.1179/1751584X12Y.0000000014

11. Kuzhir, P. P.; Bychanok, D. S.; Maksimenko, S. A.; Gusinski, A. V.; Ruhavets, O. V.; Kuznetsov, V. L.; Moseenkov, S. I.; Jones, C.; Shenderova, O.; Lambin, P. Solid State Sci. 2009, 11, $1762-1767$. doi:10.1016/j.solidstatesciences.2008.12.003

12. Gu, W.; Peters, N.; Yushin, G. Carbon 2013, 53, 292-301. doi:10.1016/j.carbon.2012.10.061

13. Hantel, M. M.; Presser, V.; McDonough, J. K.; Feng, G.; Cummings, P. T.; Gogotsi, Y.; Kötz, R. J. Electrochem. Soc. 2012, 159, A1897-A1903. doi:10.1149/2.006212jes

14. Kuznetsov, V. L.; Chuvilin, A. L.; Butenko, Y. V.; Mal'kov, I. Y.; Titov, V. M. Chem. Phys. Lett. 1994, 222, 343-348. doi:10.1016/0009-2614(94)87072-1

15. Kuznetsov, V. L.; Chuvilin, A. L.; Moroz, E. M.; Kolomiichuk, V. N.; Shaikhutdinov, S. K.; Butenko, Y. V.; Mal'kov, I. Y. Carbon 1994, 32 , 873-882. doi:10.1016/0008-6223(94)90044-2

16. Cebik, J.; McDonough, J. K.; Peerally, F.; Medrano, R.; Neitzel, I.; Gogotsi, Y.; Osswald, S. Nanotechnology 2013, 24, 205703. doi:10.1088/0957-4484/24/20/205703

17. Banhart, F. Rep. Prog. Phys. 1999, 62, 1181-1222. doi:10.1088/0034-4885/62/8/201

18. Gao, Y.; Zhou, Y. S.; Park, J. B.; Wang, H.; He, X. N.; Luo, H. F.; Jiang, L.; Lu, Y. F. Nanotechnology 2011, 22, 165604. doi:10.1088/0957-4484/22/16/165604

19. Yang, Y.; Liu, X.; Guo, X.; Wen, H.; Xu, B. J. Nanopart. Res. 2011, 13, 1979-1986. doi:10.1007/s11051-010-9951-0

20. Zeiger, M.; Jäckel, N.; Mochalin, V. N.; Presser, V. J. Mater. Chem. A 2016, 4, 3172-3196. doi:10.1039/c5ta08295a
21. Bartelmess, J.; Giordani, S. Beilstein J. Nanotechnol. 2014, 5, 1980-1998. doi:10.3762/bjnano.5.207

22. Walker, P. L.; McKinstry, H. A.; Wright, C. C. Ind. Eng. Chem. 1953, 45, 1711-1715. doi:10.1021/ie50524a033

23. Todt, M.; Bitsche, R. D.; Hartmann, M. A.; Fischer, F. D.; Rammerstorfer, F. G. Int. J. Solids Struct. 2014, 51, 706-715. doi:10.1016/j.ijsolstr.2013.10.038

24. Suárez-Garcia, F.; Martínez-Alonso, A.; Díez Tascón, J. M. J. Anal. Appl. Pyrolysis 2002, 63, 283-301. doi:10.1016/S0165-2370(01)00160-7

25. Smilgies, D.-M. J. Appl. Crystallogr. 2009, 42, 1030-1034. doi:10.1107/S0021889809040126

26. Short, M. A.; Walker, P. L., Jr. Carbon 1963, 1, 3-9. doi:10.1016/0008-6223(63)90003-4

27. Millikan, M. Nutritional Metals in Foods by AAS. In Atomic Absorption Spectroscopy; Farrukh, M. A., Ed.; InTech, 2012; pp 143-166. doi: $10.5772 / 27556$

28. Kokubo, K.; Matsubayashi, K.; Tategaki, H.; Takada, H.; Oshima, T. Nanotechnology 2008, 2, 327-333. doi:10.1021/nn700151z

29. Chao, T.-C.; Song, G. X.; Hansmeier, N.; Westerhoff, P.; Herckes, P.; Halden, R. U. Anal. Chem. 2011, 83, 1777-1783. doi:10.1021/ac1031379

30. Shi, J.; Le Maguer, M.; Bryan, M.; Kakuda, Y. J. Food Process Eng. 2003, 25, 485-498. doi:10.1111/j.1745-4530.2003.tb00647.x

31. Shi, J.; Le Maguer, M.; Bryan, M. Lycopene from tomatoes. In Functional Foods, Biochemical and Processing Aspects; Mazza, G.; Le Maguer, M.; Shi, J., Eds.; CRC Press, 2002; Vol. 2, pp 135-167. doi:10.1201/9781420012873.ch4

32. Kanasawud, P.; Crouzet, J. C. J. Agric. Food Chem. 1990, 38 , 1238-1242. doi:10.1021/jf00095a018

33. Chuvilin, A.; Kaiser, U.; Bichoutskaia, E.; Besley, N. A.; Khlobystov, A. N. Nat. Chem. 2010, 2, 450-453. doi:10.1038/nchem.644

34. Butenko, Yu. V.; Šiller, L.; Hunt, M. R. C. Carbon Onions. In Handbook of Nanophysics: clusters and fullerenes; Sattler, K. D., Ed.; CRC Press, 2010; pp 1-18.

35. Rao, C. N. R.; Subrahmanyam, K. S.; Ramakrishna Matte, H. S. S.; Govindaraj, A. Graphene: Synthesis, Functionalization and Properties. In Graphene and its fascinating attributes; Pati, S. K.; Enoki, T.; Rao, C. N. R., Eds.; World Scientific Publishing, 2011; pp 1-32. doi:10.1142/9789814329361_0001 


\section{License and Terms}

This is an Open Access article under the terms of the Creative Commons Attribution License

(http://creativecommons.org/licenses/by/2.0), which permits unrestricted use, distribution, and reproduction in any medium, provided the original work is properly cited.

The license is subject to the Beilstein Journal of Nanotechnology terms and conditions:

(http://www.beilstein-journals.org/bjnano)

The definitive version of this article is the electronic one which can be found at:

doi:10.3762/bjnano.7.67 